\title{
PENGARUH HARGA TIKET DAN ATRAKSI WISATA TERHADAP KEPUASAN WISATAWAN SITUGUNUNG SUSPENSION BRIDGE SUKABUMI
}

\author{
Umban Adi Jaya ${ }^{1}$ \\ Program Studi Manajemen, Institut Manajemen Wiyata Indonesia \\ Email: umban.adi@imwi.ac.id \\ Tesa Amellia ${ }^{2}$ \\ Program Studi Manajemen, Institut Manajemen Wiyata Indonesia \\ Email: tesa.amellia@gmail.com
}

\begin{abstract}
Abstrak
Maksud dari riset ini adalah guna mengetahui dampak harga tiket wisata dan pesona wisata terhadap kepuasan pengunjung di Jembatan Gantung Situgunung Sukabumi. Metode yang dipakai dalam survei ini adalah metode survei deskriptif kuantitatif, dimana kuesioner disebarkan kepada 100 sampel atas memakai metode Objective Sampling berdasarkan wisata Situgunung. Hasil riset ini memperlihatkan bahwa nilai Adjusted R-squared sebesar 71,8\% yang memperlihatkan bahwa kepuasan pengunjung didampaki secara positif dan signifikan oleh harga tiket dan pesona wisata atas persamaan regresi $\mathrm{Y}=9,828+0,433 \mathrm{X} 1+1,157 \mathrm{X} 2$. Hasil analisis secara simultan memperlihatkan bahwa harga tiket dan pesona wisata berdampak terhadap kepuasan pengunjung. Uji t memperlihatkan bahwa terdapat dampak parsial antara harga tiket dan pesona wisata guna kepuasan pengunjung.
\end{abstract}

Kata Kunci : harga tiket; tempat wisata; kepuasan pengunjung

\begin{abstract}
The purpose of this study was to determine the effect of tourist ticket prices and tourist attraction on tourist satisfaction at the Situgunung Sukabumi Suspension Bridge. The method used in this survey is a quantitative descriptive survey method, where questionnaires are distributed to 100 samples using the Objective Sampling method based on Situgunung tourism. The results of this study indicate that the Adjusted R-squared value is $71.8 \%$ which indicates that tourist satisfaction is positively and significantly influenced by ticket prices and tourist attractions with the regression equation $\mathrm{Y}=9.828+0.433 \mathrm{X} 1+1.157 \mathrm{X} 2$. Simultaneous analysis results show that ticket prices and tourist attractions have an effect on tourist satisfaction. The t-test shows that there is a partial effect between ticket prices and tourist attraction for tourist satisfaction.
\end{abstract}

Keywords: ticket price; tourist attraction; tourist satisfaction 


\section{Pendahuluan}

Indonesia adalah negara yang kaya akan sumber daya alam yang mampu dimanfaatkan dalam berbagai bidang termasuk pariwisata. (Nandi, 2016). Pemerintah Republik Indonesia sangat serius dalam pengelolaan pariwisata guna memajukan kesejahteraan rakyatnya. Tidak hanya pemerintah pusat, tetapi juga tingkat kabupaten/kota melihat pariwisata sebagai sektor ekonomi yang penting. (Yuendini et al., 2019). Sehingga Dinas Pariwisata hampir didirikan di semua kalangan pemerintah kabupaten/kota di Indonesia atas misi guna mengelola dan mempromosikan potensi pariwisata masing-masing daerah. Salah satu Dinas Pariwisata yang dibentuk adalah Dinas Pariwisata Kabupaten Sukabumi. Keanekaragaman pariwisata di Sukabumi disebut GURILAPSS. Yaitu pegunungan, hutan rimba, lautan, pantai, sungai dan jasa pariwisata lainnya yang mempunyai fungsi/peran strategis bagi kegiatan ekonomi daerah dan potensi sosial secara keseluruhan.

Salah satu objek yang berada di Kabupaten Sukabumi adalah Situgunung Suspension Bridge yang terletak di Kadudampit, Cisaat Sukabumi. Situgunung adalah kawasan Taman Nasional Gunung Gede Pangrango (TNGGP) yang menghadirkan suasana keindahan alam yang berpotensi menjadi objek wisata. Situgunung setiap tahunnya mendapatkan kunjungan pengunjung yang meningkat, terbukti atas data yang diperoleh dari pusat informasi Situgunung Suspension Bridge Sukabumi. Lebih jelasnya mampu dilihat dari gambar grafik berikut :

\section{Gambar 1.}

\section{Gafik Jumlah Pengunjung Situgunung}

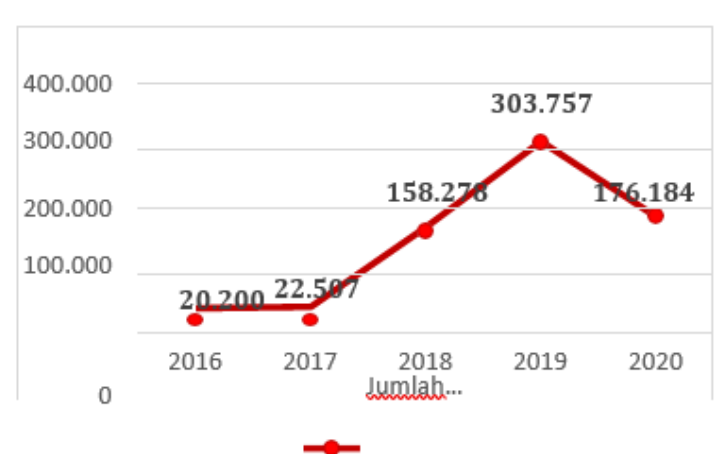

Sumber: Situgunung Suspension Bridge

Berdasarkan data yang diperoleh mampu dilihat setiap tahunnya mengalami peningkatan kunjungan pengunjung kecuali ditahun 2020 mengalami penurunan dikarenakan COVID-19 yang mempunyai aturan guna mengurangi jumlah pengunjung pengunjung. Situgunung memiliki upaya guna selalu meningkatkan pengunjung guna menikmati wisata dan keindahan alam yang tersedia di Situgunung. Berdasarkan hasil wawancara atas Kepala Resort Situgunung Bapak Asep Suganda yaitu peningkatan kunjungan pengunjung adalah peranan signifikan dalam dunia bisnis. Dalam bisnis perjalanan wisata, diperlukan beberapa elemen guna menunjang pengalaman perjalanan para pengunjung. Unsur yang di maksud adalah harga tiket yang terjangkau dan atraksi wisata yang menarikHarga tiket masuk dan harga tiket atraksi wisata di Situgunung menjadi pertimbangan pengunjung guna berkunjung. Harga tiket masuk Situgunung sangat terjangkau di weekday atas harga Rp16.000,00 maupun di weekend atas harga Rp18.500,00 harga tersebut sudah mampu menikmati kepuasan keindahan suasana alam. Guna harga tiket masuk itu belum termasuk harga atraksi wisata. Jika pengunjung ingin mendapatkan kepuasan yang lebih, pengunjung mampu menikmati atraksi wisata yang sudah tersedia di Situgunung atas membayar harga tiket atraksi wisata. 
Atrakasi wisata adalah pesona wisata

Tabel 1.

Harga Paket Atraksi Wisata Situgunung

\begin{tabular}{|c|c|c|}
\hline No & Paket Wisata & Harga \\
\hline \multirow{7}{*}{1} & One Day Trip Regular: & \multirow{7}{*}{ Rp50.000 } \\
\hline & Insurance, Jungle Tracking, & \\
\hline & Sawer Waterfall, & \\
\hline & Situgunung & \\
\hline & Suspension & \\
\hline & Welcome Drink, Teather & \\
\hline & (Sundanse Traditional Art) & \\
\hline \multirow{7}{*}{2} & One day Trip Regular Plus: & \multirow{7}{*}{ Rp60.000 } \\
\hline & Insurance, Jungle Tracking, & \\
\hline & Sawer Waterfall, & \\
\hline & Situgunung & \\
\hline & Suspension & \\
\hline & Welcome Drink, Teather & \\
\hline & $\begin{array}{l}\text { (Sundanse Traditional Art), } \\
\text { Red Bridge }\end{array}$ & \\
\hline
\end{tabular}

One Day Trip VIP:

Insurance, Jungle Tracking,

Sawer Waterfall,

Situgunung Lake,

3 Suspension Bridge, Teather

(Sundanse Traditional Art),

Red Bridge, VIP Acces,

Shutle Transport (Front

Office-Resto Balcony),

Welcome Drink (All

You Can Eat)

One Day Trip VIP + Lunch:

Insurance, Jungle Tracking,

Sawer Waterfall,

Situgunung Lake,

4 Suspension Bridge, Teather

(Sundanse Traditional Art),

Red Bridge, VIP Acces,

Shutle Transport (Front

Office- Resto Balcony),

Welcome Drink (All You

Can Eat)

Sumber: Situgunung Suspension Bridge guna menarik pengunjung (Kastolani et al., 2014). Tempat wisata di Situgunung mempunyai pesona yang menarik seperti atraksi wisata alam dan atraksi buatan. Atraksi wisata alam yang ada di Situgunung seperti danau, curug sawer, dan berendam di sungai limpahan curug sawer serta pemandangan alamnya pun menjadi pesona tersendiri. Sedangkan guna atraksi buatan di Situgunung seperti jembatan gantung terpanjang se-Asia Tenggara, jembatan merah, dan atraksi budaya kesenian. Atas atraksi- atraksi wisata yang tersedia di Situgunung pengunjung akan mendapatkan kepuasan jika atraksi tersebut memang benar menarik tetapi jika tidak pengunjung tidak akan mendapatkan kepuasan. mampu disimpulkan bahwa kepuasan pengunjung objek wisata Situgunung atas kenaikan jumlah pengunjung didampaki oleh harga tiket dan atraksi wisata.

Riset yang dilaksanakan oleh Rp100.00 (Alvianna, 2017) memperlihatkan bahwa 0 harga memiliki dampak yang signifikan terhadap kepuasan pengunjung. Hal ini dikarenakan pengunjung beranggapan bahwa harga sebanding atas kepuasan saat berwisata. Tempat wisata yang menawarkan harga yang relatif terjangkau diharapkan kedepannya mampu mempertahankan pengunjung agar senantiasa tetap puas atas harga yang harus dikeluarkan saat berwisata. Namun dalam riset (Irfan, 2019) hasil survei Rp125.00 memperlihatkan bahwa harga tidak 0 memdampaki kepuasan pelanggan.

Riset yang dilaksanakan oleh (Handayani et al., 2019) Pesona wisata memdampaki kepuasan pengunjung. Pesona juga adalah faktor yang memdampaki keputusan perjalanan di suatu daerah maksud wisata karena "Tanpa Pesona, Tidak Ada Maksud". Selanjutnya riset lain yang dilaksanakan (Ximenes et al., 2020) bahwa 
hasil riset memperlihatkan atraksi wisata memdampaki kepuasan pengunjung. Riset ini juga didukung oleh riset (Saway et al., 2021) hasil riset memperlihatkan atraksi wisata mampu memdampaki suatu objek wisata untk pengunjung yang berkunjung. Semakin menariknya atraksi akan meningkatkan pengunjung guna mengunjungi tempat wisata dan akan merasakan kepuasan.

Riset ini bermaksud guna mengidentifikasi dan menganalisis faktorfaktor yang memdampaki kepuasan pengunjung. Peneliti mengambil judul guna diteliti yaitu "Dampak Harga Tiket Wisata dan Atraksi Wisata terhadap kepuasan Pengunjung Situgunung Suspension Bridge Sukabumi".

\section{Metode Riset}

Riset ini memakai metode riset deskriptif dan kuantitatif. Populasi riset ini adalah para pengunjung yang sudah berkunjung ke Situgunung Suspension Bridge Sukabumi. Sampel guna survei ini adalah pengunjung yang berkunjung ke Jembatan Gantung Situgunung Sukabumi. Para peneliti tidak mengetahui jumlah pengunjung di Situgunung, sehingga mereka memakai rumus guna mencari sampel.

\section{HASIL RISET DAN PEMBAHASAN}

A. Analisis Deskriptif Responden

Hasil riset diperoleh jumlah responden sebanyak 100 orang pengunjung Situgunung Suspension Bridge Sukabumi yang mengisi kuesioner. Peneliti memperoleh statistik deskriptif dan deskriptif dari profil responden. Konon, berdasarkan jenis kelamin responden, mayoritas adalah perempuan, dan berdasarkan usia, $61 \%$ dominan antara usia 15-25. Sebanyak $73 \%$ orang dalam kelompok usia ini cenderung bebas bepergian, terutama guna menikmati pemandangan, alam, dan atraksi Sitgunun, Dari perspektif profesional, mayoritas responden adalah 60\% mahasiswa. Adapun hasil berdasarkan jumlah kunjungan yaitu $51 \%$ responden menjawab $>2$ kali kunjungan mengartikan responden merasakan kepuasan saat berwisata di Situgunung.

B. Analisis Deskriptif Variabel

Dari hasil analisis deskriptif variabel memperoleh tanggapan reponden terhadap variabel- variabel yang memaparkan hubungan antara indikator-indikator dalam kuesioner. Tanggapan responden mengenai variabel harga tiket yang diwakili 13 pernyataan memperlihatkan $49 \%$ responden menyatakan setuju terhadap indikatorindikator dalam memdampaki harga tiket, terutama harga tiket masuk dan harga tiket paket atrakksi wisata Situgunung sesuai atas pengalaman yang didapatkan. Dan tanggapan responden mengenai variabel atraksi wisata yang diwakili 7 pernyataan memperlihatkan $61 \%$ responden menyatakan sangat setuju terhadap indikator-indikator dalam memdampaki atraksi wisata, terutama danau Situgunung yang memiliki pesona tinggi yang mampu dinikmati keindahan pemandangannya yang menenangkan, sedangkan tanggapan responden mengenai variabel kepuasan pengunjung diwakili 16 pernyataan memperlihatkan $51 \%$ responden menyatakan sangat setuju terhadap indikator- indikator kepuasan pengunjung, terutama merasa puas menikmati danau Situgunung sesuai atas harapan.

C. Uji Instrumen

1. Uji Validitas

Uji validasi dipakai guna mengukur efektivitas survei yang dibagikan kepada responden, sedangkan Uji reliabilitas dilaksanakan guna mengukur dan konsistensi pengisian kuesioner. (Indriani \& Kuswoyo, 2017). Adapun hasil uji validitas memakai perhitungan rhitung > rtabel $(0,195)$ maka instrumen dikatakan valid, hal ini menandakan bahwa semua item 
pernyataan pada variabel harga tiket, atraksi wisata dan kepuasan pengunjung bersifat valid.

2. Uji Reliabilitas

Hasil uji reliabilitas variabel dikatakan reliabel jika nilai cronbach alpha $>0,60$. Pada hasil riset ini variabel tarif sebesar 0,960 yang dinyatakan reliabel, variabel pesona wisata dinyatakan reliabel sebesar 0,830 , dan variabel kepuasan pengunjung dinyatakan reliabel sebesar 0,925 .

D. Uji Asumsi Klasik

1. Uji Normalitas

Uji normalitas dipakai guna mengetahui apakah data yang diteliti berdistribusi normal (Taufik, 2019). Uji normalitas dalam riset ini memakai uji satu sampel Kolmogorov-Smirnov dan hasil data memperlihatkan nilai signifikansi Asymp. Sig. (2 tailed) lebih besar dari 0,050 yaitu sebesar 0,2 , oleh karena itu, mampu disimpulkan bahwa data riset berdistribusi normal.

2. Uji Multikolinearitas

Uji multikolinearitas dilaksanakan guna menentukan apakah model regresi mendeteksi adanya korelasi (bebas) dari variabel independent (Ningsih \& Dukalang, 2019). Multikolinearitas mampu diuji atas menguji tolerance dan variance inflation factor (VIF). Cutoff umum guna multikolinearitas sama atas toleransi 0,10 atau nilai VIF lebih besar dari 10. Berdasarkan hasil perhitungan variabel harga tiket (X1) dan atraksi wisata (X2) meunjukkan nilai yang sama yaitu nilai tolerace sebesar 0,661 dan nilai VIF sebesar 1,512. mampu dilihat nilai VIF $<10$ dan nilai tolerance $>0,10$, maka mampu diartikan bahwa antar variabel bebas tidak terjadi multikolinearitas.

3. Uji Heteroskedastisitas

Uji varians non-homogen pada model regresi guna melihat apakah ada ketidaksetaraan varians dari satu residual ke yang lain. Dari hasil scatterplot dalam olah data spss bahwa titik-titik terlihat tidak berpola dan terlihat menyebar secara acak serta tersebar baik dibawah dan di atas angka 0 pada sumbu Y. Oleh karena itu, kita mampu menyimpulkan bahwa tidak ada masalah dispersi yang tidak seragam.

4. Uji Regresi Linear Berganda

Analisis regresi linear berganda dipakai guna mengetahui besarnya dampak antara variabel independet yaitu Harga Tiket (X1) dan Atraksi Wisata (X2) terhadap variabel dependent yaitu Kepuasan Pengunjung (Y) (Makalew et al., 2019). Hasil uji regresi berganda atas memakai program SPSS 26 for Windows dan persamaan regresi berganda berikut. $\mathrm{Y}=9,828+0,433 \mathrm{X} 1$ $+1,157 \mathrm{X} 2$ Nilai persamaan regresinya adalah:

a. Nilai konstanta $=9,828$ yang berarti bahwa jika variabel harga tiket dan atraksi wisata maka akan ada kepuasan pengunjung sebesar 9,828.

b. Nilai koefisien variabel Harga Tiket $=0,433$ memperlihatkan bahwa jika variabel harga tiket mengalami kenaikan sebesar 1 (satu) maka kepuasan pengunjung akan meningkat sebesar 0,433 .

c. Nilai koefisien variabel atraksi wisata $=1,157$ memperlihatkan bahwa peningkatan 1 pada variabel pesona wisata akan meningkatkan kepuasan pengunjung sebesar 1,157.

5. Uji Hipotesis

a. Uji t (Uji Parsial) dipakai guna memperlihatkan seberapa besar kontribusi variabel independen dalam menjelaskan perubahan variabel dependen (Indrawan, 2019). Berikut hasil uji t yang telah dilaksanakan yakni Hasil uji $t$ variabel harga tiket (X1) terhadap variabel kepuasan pengunjung (Y). Tingkat signifikansi guna variabel tarif adalah 0,000 yang lebih kecil dari 0,05 , tetapi nilai t-hitung yang 
dihasilkan adalah 7,449 yang lebih besar dari nilai t-tabel $(\mathrm{Dk}=\mathrm{n}-\mathrm{k})$ = 1,98, sehingga Ho ditolak dan Ha diterima. Maka asumsi ini memperlihatkan bahwa "Harga tiket berdampak positif terhadap kepuasan pengunjung" diterima. Hasil uji $\mathrm{t}$ variabel tempat wisata (X2) terhadap variabel kepuasan pengunjung $(\mathrm{Y})$, tingkat signifikansi variabel tempat wisata adalah 0,000 lebih kecil dari 0,05 , dan nilai $\mathrm{t}$ hitung lebih besar dari 7,117 , nilai $\mathrm{t}$ tabel $(\mathrm{Dk}=\mathrm{nk})=1,98$; Oleh karena itu, Ho ditolak dan $\mathrm{C}$ diterima. hipotesis yang diajukan adalah "atraksi wisata berdampak positif dan signifikan terhadap kepuasan pengunjung". Itu diterima.

b. Uji F (Uji Simultan) Variabel bebas dipakai guna menentukan apakah variabel terikat yang dipelajari bersama memiliki dampak yang signifikan (simultan) (Jayanti, 2014). Hasil olah data atas SPSS memperlihatkan bahwa variabel harga tiket dan atraksi wisata memiliki nilai $\mathrm{F}$ hitung sebesar $126,902>3,09(\mathrm{DK}=\mathrm{n}-3-1=3,09)$ dan nilai signifikansi pada variabel harga tiket dan atraksi wisata lebih kecil dari nilai signifikansi sebesar $0,000<0,05$. Oleh karena itu, mampu disimpulkan bahwa baik harga tiket maupun pesona wisata berdampak terhadap kepuasan pengunjung.

c. Koefisien Determinasi

Koefisien determinan dilaksanakan atas maksud guna mengukur kontribusi variabel independent terhadap variabel dependent (Meilawati et al., 2019). Koefisien determinasi memiliki nilai antara 0 dan 1. Berdasarkan hasil pengolahan data, koefisien determinasi yang disesuaikan (R2) sebesar 0,718= $71,8 \%$, variabel harga tiket dan atraksi secara bersama-sama memdampaki variabel kepuasan pengunjung sebesar $71,8 \%$, dan sisanya mampu disimpulkan bahwa 28,2 berdampak terhadap 28.2. \% Didampaki oleh faktor di luar riset.

\section{Hasil Riset dan Pembahasan}

\section{Dampak Harga Tiket terhadap Kepuasan Pengunjung}

Berdasarkan hasil Survei Pengunjung Situgunung mampu disimpulkan bahwa tarif berdampak langsung terhadap kepuasan pengunjung. Hal ini terlihat dari hasil perhitungan statistik regresi nilai $\mathrm{t}$ hitung sebesar 7,449, nilai signifikansi sebesar 0,000 yang lebih kecil dari 0,05 , dan koefisien regresi positif sebesar 0,433 . Oleh karena itu, hipotesis H1 dalam riset ini diterima, yaitu "Harga tiket berdampak positif dan signifikan terhadap kepuasan pengunjung" yang artinya penentuan harga yang ditawarkan menjadi kunci utama guna membentuk kepuasan pengunjung. Hasil riset ini didukung riset terdahulu yang telah dilaksanakan oleh Alvianna, et,al (2017) bahwa hasil harga yang ditawarkan sebanding atas kendaraan yang dinikmati pengunjung, sehingga hasil harga juga berdampak signifikan terhadap kepuasan pengunjung.

2. Dampak Atraksi Wisata terhadap Kepuasan Pengunjung

Berdasakan hasil riset pada pengunjung Situgunung mampu disimpulkan bahwa atraksi wisata secara langsung berdampak terhadap kepuasan pengunjung. Hal ini terlihat dari hasil perhitungan regresi statistik. Nilai t-hitung sebesar 7,117 , nilai signifikansi 0,000 yang lebih kecil dari 0,05, dan koefisien regresi positif sebesar 1,157. Oleh karena itu, hipotesis $\mathrm{H} 2$ dalam riset ini diterima. Atas kata lain "tempat wisata berdampak positif dan signifikan terhadap kepuasan pengunjung". Salah satu pesona Situgunung yang diminati pengunjung adanya danau yang mampu dinikmati keindahan pemandangannya. Adanya atraksi wisata tersebut, pengunjung akan merasa 
menikmati wisata atas keindahan yang menenagkan yang membuat kepuasan pengunjung. Hasil riset ini didukung oleh riset Ximenes, dkk (2020) bahwa variabel atraksi wisata berdampak positif dan signifikan terhadap kepuasan pengunjung.

\section{Dampak Harga Tiket dan Atraksi Wisata tehadap Kepuasan Pengunjung}

Berdasarkan hasil survei pengunjung Situgunung mampu disimpulkan bahwa harga tiket dan atraksi berdampak positif signifikan terhadap kepuasan pengunjung. Hal ini diperoleh dari hasil statistik uji regresi, nilai $\mathrm{F}$ hitung sebesar 126,902 > F Tabel 3,09, nilai signifikansi $0,000<0,05$, dan koefisien determinasi yang disesuaikan (R2) sebesar $0,718=71,8 \%$. dia. Variabel harga tiket dan atraksi wisata secara bersamasama memdampaki $71,8 \%$ variabel kepuasan pengunjung, dan sisanya $28,2 \%$ didampaki oleh faktor selain variabel survei. Oleh karena itu, H3 guna riset ini diterima. Singkatnya, "harga tiket dan atraksi berdampak positif dan signifikan terhadap kepuasan pengunjung". Hasil riset ini didukung oleh riset Alvianna, et,al (2017) dan riset Saway, dkk (2021) mampu disimpulkan bahwa harga tiket dan atraksi berdampak positif signifikan terhadap kepuasan pengunjung.

\section{Simpulan}

Simpulan dari riset dampak Harga Tiket dan Atraksi Wisata terhadap Kepuasan Pengunjung antara lain:

1. Hasil uji t memperlihatkan bahwa tarif berdampak positif signifikan terhadap kepuasan pengunjung.

2. Hasil uji $\mathrm{t}$ memperlihatkan bahwa terdapat dampak positif yang signifikan terhadap kepuasan pengunjung antar atraksi wisata.

3. Hasil uji F memperlihatkan bahwa harga tiket dan pesona wisata berdampak positif signifikan terhadap kepuasan pengunjung. Jika nilai koefisien determinan RSquere yang disesuaikan adalah 0,718 atau $71,8 \%$.

\section{Saran}

Setelah melakukan riset, peneliti akan memperlihatkan anjuran yang mampu dijadikan bahan pertimbangan yaitu :

1. Bagi cakupan akademik, hasil riset ini diharapkan mampu menambah wawasan, pengetahuan, dan kajian literatur terkait harga tiket dan tempat wisata. Khususnya bagi peneliti selanjutnya yang ingin menggali lebih dalam mengenai kepuasan pengunjung. Oleh karena itu, peneliti selanjutnya sebaiknya mengubah variabel bebas atas mengganti atau menambahkan variabel tersebut. Sehingga akan memberikan hasil yang lebih objektif dan canggih.

2. Bagi penulis, dalam riset ini adalah bagian dari dari proses belajar yang diharapkan, penulis menyadari bahwa riset variabel harga tiket dan atraksi wisata terhadap kepuasan pengunjung masih terdapat kekurangan dan guna kedepannya penulis mampu mengembangkan riset ini atas maksimal sehingga mampu menambah wawasan dan memperjelas makna riset.

3. Bagi objek wisata SitugunungSuspension Bridge Sukabumi, dalam melakukan strategi penentuan harga tiket hendaknya pihak Situgunung memberikan harga terbaik dan terjangkau bagi pengunjung. Alangkah baiknya jika Jembatan Gantung Situgunung Sukabumi sesekali mengadakan promosi diskon guna menarik pengunjung berkunjung ke Situgunung.

4. Suspension Bridge Sukabumi. Dan guna atraksi wisata guna meningkatkan atraksi seperti wahana permainan yang sesuai konsep alam dan guna atraksi kesenian teater, tarian dan pertunjukkan budaya lainnya agar meningkatkan tampilan yang lebih menarik dan bervariasi agar pengunjung tertarik guna melihat atraksi tersebut.

\section{Daftar Pustaka}

Alvianna, Stella. (2017). Analisis Pengaruh Harga, Produk, Dan Kualitas Layanan Terhadap Kepuasan Wisatawan Di Taman Wisata Air Wendit Kabupaten Malang. 
Jurnal Pariwisata Pesona, 2(1), 12.

Ariatama, Fernando. (2017). Analisa Kelayakan Komponen Daya Tarik Destinasi Wisata Pulau Kemaro. Politeknik Negeri Sriwijaya.

Fitroh, Syakir Kamil Ainul, Hamid, Djamhur, \& Hakim, Luchman. (2017). Pengaruh Atraksi Wisata dan Motivasi Wisatawan Terhadap Keputusan Berkunjung (Survei pada Pengunjung Wisata Alam Kawah Ijen). Jurnal Administrasi Bisnis, 42(2), $18-25$.

Handayani, Sri, Wahyudin, Nanang, \& Khairiyansyah, Khairiyansyah. (2019). Fasilitas, Aksesibilitas dan Daya Tarik Wisata Terhadap Kepuasan Wisatawan. Jurnal Ilmiah Manajemen Dan Bisnis, 20(2), 123-133.

Irawan, Handi. (10AD). Prinsip Kepuasan Pelanggan, Jakarta: PT. Elex Media Komputindo.

Irfan, Andi Muhammad. (2019). Pengaruh Kualitas Pelayanan, Harga Dan Fasilitas Yang Diberikan Kenari Waterpark Bontang Terhadap Tingkat Kepuasan Pelanggan. Al-Infaq: Jurnal Ekonomi Islam, 9(2), 82-97.

Jaya, Umban Adi, Bagja, Santun Insan, \& Somantri, Bambang. (2020). Pengaruh Price dan Product Quality Terhadap Costumer Loyalty Internet Indosat Ooredo di Sukabumi. Cakrawala, 3(1), 33-42.

Kotler, Philip, \& Keller, Kevin Lane. (2016a). Manajemen Pemasaran Edisi 15e. PT. Indeks Kelompok Gramedia. Jakarta.
Kotler, Philip, \& Keller, Kevin Lane. (2016b). Marketing management (15th global ed.). England: Pearson.

Lupiyoadi, Rambat. (2018). Manajemen Pemasaran Jasa: Berbasis Kompetensi; Edisi 3.

Nurcahyo, R. Jati. (2019). Of Tourism And Economic. Journal of Tourism and Economic Vol, 2(1), 57-65.

Saway, Winny Virginia, Alvianna, Stella, Lasarudin, Alwin, \& Hidayatullah, Syarif. (2021). Dampak Atraksi, Amenitas Dan Aksesibilitas Pantai Pasir Putih Kabupaten Manokwari Terhadap Kepuasaan Wisatawan Berkunjung. Jurnal Pariwisata Budaya: Jurnal Ilmiah Pariwisata Agama Dan Budaya, 6(1), 1-8.

Sunarji, Aji. (2016). Analisis Rasio Keuangan Dalam Memprediksi Kondisi Financial Distress Perusahaan Manufaktur Yang Terdaftar di Bursa Efek Indonesia (Studi Kasus pada Perusahaan Tekstil dan Garmen periode 2011-2015). Fakultas Ekonomi dan Bisnis Unpas Bandung.

Suryadana, M. (2015). Pengantar pemasaran pariwisata.

Tjitono, Fandy. (2017). Service Management Mewujudkan Layanan Prima.

Ximenes, Domicilia, Setioko, Danang, Rachmadani, Aprilia, \& Roejinandari, Nanny. (2020). Pengaruh Atraksi dan Amenitas Terhadap Kepuasan Pengunjung di Wisata Gunung Fatuleu Kabupaten Kupang. 